249 EFFECTIVENESS OF A DOSE-BASED CONCEPT FOR DUST CONTROL - A LONGITUDINAL STUDY OF COAL MINERS' IN THE RUHR AREA

${ }^{1} \mathrm{M}$ Yong, ${ }^{1} \mathrm{~L}$ Anderle, ${ }^{2} \mathrm{R}$ Derwall, ${ }^{2} \mathrm{H}$ Lenaerts, ${ }^{1} \mathrm{P}$ Morfeld. ${ }^{1}$ Institute for Occupational Epidemiology and Risk Assessment, Evonik Industries AG; ${ }^{2}$ Department of Occupational Medicine, RAG AG

\subsection{6/oemed-2018-ICOHabstracts. 1253}

Introduction A dose-based concept for dust control has been implemented in German coal mining since 1991. This concept foresees that miners with exposure to fibrogenic dusts cannot exceed a cumulative exposure of 440 total dust exposure value (TDEV) per year within an assessment period of 2 years. TDEV is defined to be a function of the 8 hour shift average concentration and the number of performed shifts. The Regulation of Health Protection in Mining set the work place limit at an 8 hour average of $4.0 \mathrm{mg} / \mathrm{m} 3$ for respirable dust and $0.2 \mathrm{mg} / \mathrm{m} 3$ for quartz component (>5\% mass). This concept considers the exposure limits, and regulatory changes connecting to working durations, hence, cumulative personal exposure to dust. The present study evaluates the effectiveness of this concept, after 37 years of implementation.

Methods A complete inception cohort of 1369 coal miners who started working underground in the Ruhr area in 19741979 has been provided with continuous health surveillance. Concerning the course of lung function (VCmax, FEV1, FEV1/VCmax), the impacts of exposure metrics are estimated using Generalised Estimation Equation models. The risk of developing coal workers' pneumoconiosis (CWP) category $\geq 0$ / 1 is estimated by Cox regression.

Results Cumulative coal dust exposure shows no negative impact on VCmax and FEV1, but a very low but statistically significant effect on FEV1/VCmax. Cumulative exposure to coal dust shows a significant slightly increased risk of developing CWP $\geq 0 / 1$. In an alternative model considering average dust concentration and exposure duration, increased risk is attributed to exposure duration, but not to dust concentration. Discussion The dust control programme connecting regulation of working duration incorporate with continuous health surveillance seems to be effective for preventing CWP in German coal mining after 37 years of follow-up.

\section{CAUSES AND COMMON FEATURES AMONG HAIRDRESSERS WITH RESPIRATORY SYMPTOMS AT WORK}

J Hiller*, T Lippert, R Seidel, H Drexler. Institute of Occupational, Social and Environmental Medicine, Univ. of Erlangen-Nürnberg, Erlangen, Germany

\subsection{6/oemed-2018-ICOHabstracts.1254}

Introduction Respiratory symptoms at work are common among hairdressers throughout the world. However, their ties to clearly identifiable causes have been less compelling. Among others ammonium persulfate (AP), a common compound of hair dyes, has been reported to cause occupational asthma. But other chemical, allergenic and irritative substances and unfavourable air conditions (damp, dust, fume) are widespread in hairdressing saloons as well, making even the underlying pathomechanisms ill-defined. For a better understanding of work related airway diseases the objective of this study is to describe common features and potential causes in affected hairdressers.
Methods Hairdressers with respiratory symptoms at work who were referred to a specialised outpatient clinic between May 2012 and May 2017 were consecutively included in a case series. During presentation various anamnestic data as well as medical examinations including pulmonary function and allergy testing were compiled. Data were analysed using SPSS Statistics.

Results Hairdressers comprised 53\% $(n=105)$ of the patients referred to our clinic for occupational respiratory diseases. The hairdressers were predominantly female (91.4\%) with a mean age of 39.2 (18-70). 15.2\% showed a clear positive reaction to $\mathrm{AP}$ in the skin prick testing, while another 1,9\% had an externally documented positive finding.

Conclusion This is to our knowledge the largest examined collective of symptomatic hairdressers and is therefore an important source to identify similarities and possible causes. A classification into four different subgroups can be suggested: 1. Patients with an obstructive airway disease (OAD) and proven AP-sensitisation; 2. Patients with OAD, no AP-sensitisation and no other known extra-professional condition explaining the symptoms; 3. Patients with OAD and a known extra-professional condition; 4. Symptomatic patients without verifiable OAD. Therefore, the cause for the work-related symptoms could not always be entirely clarified but a causal relationship seems likely for group 1 and possible for group 2 .

\section{CASE STUDY OF THE FIRST OCCUPATIONAL COMPENSATION CLAIM OF ASBESTOS-RELATED DISEASE IN INDONESIA}

\footnotetext{
${ }^{1,2}$ Anna Suraya*, ${ }^{2}$ Ade Dwi Lestari, ${ }^{3}$ Karen Gunderson. ${ }^{1}$ Community Medicine Department, University of Indonesia, Jakarta, Indonesia; ${ }^{2}$ Occupational Safety and Health Department, Binawan Institute Health Science, Jakarta, Indonesia; ${ }^{3}$ Developing World Outreach Initiative, American Industrial Hygiene Association, Santa Rosa, California, USA
}

\subsection{6/oemed-2018-ICOHabstracts. 1255}

Introduction Chrysotile asbestos has been imported into Indonesia and processed in numerous factories since 1950. Despite many years of asbestos exposures, no claim of occupational asbestos-related disease has been recognised and compensated by the National Labour Insurance program.

Methods An employee from an asbestos gland packing factory was selected to undergo an examination in accordance with the seven step process required for occupational disease diagnosis set by the Indonesian Ministry of Health (Regulation \#56, 2016) and criteria set by the American Thoracic Society The employee was interviewed and underwent a physical exam, ILO standard chest radiography, spirometry, and highresolution CT (HRCT) imaging.

Result The employee had over 23 years of occupational asbestos exposure and presented with chronic non-productive cough, exhaustion, low body weight, and intermittent chest pain. The ILO standard radiograph and HRCT were consistent with asbestosis and the spirometry test showed a mild restrictive ventilator defect. The case was reported to the district Ministry of Manpower and compensation of 74 million rupiah (USD 5000) was awarded by the National Labour Insurance Program in late 2016. This amount was calculated based on the percentage of physical disability and the base salary of the worker.

Discussion This is the first case of asbestos-related disease to receive compensation from the Indonesian government. It is important because asbestos hazards are relatively unknown by both the public and workers in Indonesia. Finding more asbestos-related disease cases is an urgent concern, especially among 